\title{
An Analysis of Enterprise Resource Planning System Usage to Improve Busi- ness Process Performance
}

\author{
Soobia Saeed ${ }^{1,}{ }^{*}$, Muhammad Qasim Nizamani ${ }^{2}$, Farheen Qasim Nizamani ${ }^{2}$, Muhammad Ali Nizamani ${ }^{3}$, \\ Pardep Kumar ${ }^{4}$, Muhammad Memon ${ }^{5}$ \\ ${ }^{1}$ Department of Software Engineering, ILMA University Karachi, Pakistan \\ ${ }^{2}$ Department of Media \& Communication Studies, Uinversity of Sindh, Jamsoro, Pakistan \\ ${ }^{3}$ Department of Information Technology, University of Sindh, Jamshoro, Pakistan \\ ${ }^{4}$ Department of Software Engineering, QUEST, Nawabshah, Pakistan \\ ${ }^{5}$ Institute of Business Administration, Uinversity of Sindh, Jamsoro, Pakistan \\ ${ }^{*}$ Corresponding author: soobiasaeed1@gmail.com
}

\section{Abstract}

\begin{abstract}
Enterprise Resource Planning (ERP) is an information system which integrates business functions and processes. ERP systems are widely used in different commercial organizations and industries. For a number of reasons, ERP can be the cause of success in an organization and help improve individual's performance in an organization by supporting better decision making. It is especially useful in helping an organization improve its productivity, reduce its operational cost and improve quality by efficient use of resources and effective communication. ERP implementation strategy greatly influences an industry's business process performance and can help lower organizational resistance to it. It also plays a vital role for business process performance because there is a passionate reaction to ERP that is a characteristic response to change connected with new innovation in an organization. This work is conducted to evaluate the ERP implementation and its influence on enterprise infrastructure, especially how the business performance is improved. The method used in this study is survey based, using interviews from more than 100 experts from different organizations in Karachi, Pakistan. The results show significant role of ERP system in raising business process performance of the organizations. Overall, ERP system impacts heavily an industry in terms of business process performance and also helps improve individual performance, considering how organizational resistance is managed using various strategies and communicating well.
\end{abstract}

Keywords-Enterprise resource planning; communication; organizational resistance, business process performance

\section{Introduction}

I NNOVATION is the key for success for any modern enterprise from manufacturing to the service industry. In this modern era, the use of Enterprise Resource Planning (ERP) system has become essential for any organization aiming for production efficiency, reduction of cost on business processes, improved individual performances, flexibility and also improved quality of end product or service. Though, many organizations adopt ERP systems, but organizational resistance may impact its usage and efficacy. Therefore, managing these challenges vis-a-vis adoption of any information

ISSN: 2523-0379 (Online), ISSN: 1605-8607 (Print)

DOI: https://doi.org/10.52584/QRJ.1901.09

This is an open access article published by Quaid-e-Awam University of Engineering Science 85 Technology, Nawabshah, Pakistan under CC BY 4.0 International License. system that requires individual support needs significant strategies in change management and individual training. As the industry and firms adopt information systems for manufacturing, supply chain management (SCM) and customer support, the role of an integrated system has become significant. This is where ERP systems play a vital role in a modern organization and has shown significant performance gain for an organization.

There is an important relationship between business process performance improvement and ERP adoption [1] and it can lead to an improved the innovation in an organization. The ERP adoption is not always successful, as shown in a study exploring its adoption in Chinese small enterprise organization [2]. The ERP adoption in an organization needs to 
be managed carefully, as there is always human side to technology implementation [3] and there can be an impact of organizational resistance on its implementation [4]. The successful implementation is the result of good change management practices [5] and will help reap its benefits. Therefore, it is important to take into account the end user resistance while implementing an ERP system [6]. The individual training and performance also plays a critical role in the business process performance [7][8]. It is important to understand that training also needs proper effort and a systematic approach in order to make an impact on the business process [9][10].

In this work, we analyze the effect of relationship between the ERP system adoption and actual business process performance in an organizations in Pakistan. In this context, we examine how the organizational resistance and business performance create a positive relationship. Also, we investigate the impact of staff training on the business process performance and investigate how the individual performance has a positive relationship with the business process performance improvement. Before we explore the answers to all these questions in the context of ERP system adoption in the organizations in Pakistan, we will review the relevant state of the art.

\section{Literature Review}

In [11], the authors examined the impact of ERP system in big business asset arranging (ERP) and the performance gain of using a supply chain management (SCM) systems. There results showed a significant financial improvement using ERP systems. The results are in the perspective of a sample of 558 organizational adoptions of a ERP system and 420 SCM utilizations.

In [12], the authors explored the factors impacting the success of ERP system in Bangladesh. They surveyed different organizations and distributed 600 questionnaires among ERP system users and senior management. Their results show that business process performance can be measured using ERP systems implementation in an organization and also showed clearly that individual performance impacts the business process performance as well.

In [13], the authors analyzed the impact of ERP system adoption on the performance of medium size firms in Nigeria. It selected 329 firms in this category and used survey based approach by distributing 658 questioners, of which only 355 were useable. The main results of this study were that ERP system adoption has direct relationship with the business process performance of medium size firms and important the individual support, especially the support from the top management is vital for business process performance. Also, other factors contribute to its improvement, for example, organization culture, that impacts organizational resistance.

The authors in [14] scrutinized the role of ERP system adoption and the management control from accounting perspective and its impact on socioideological control. They distributed 972 questionnaires in the Malaysian manufacturing firms and results were gained from 114 usable questionnaires. Results showed significant impact on business performance and firms competitive advantage. Also, less important was socio-ideological control for business performance, which includes individual train-ing and development activities.

The authors in [15] explored supply chain integration with ERP system and their shared impact on the organizational performance in Indonesia. It showed ERP system's usefulness in integrating supply chain management leading to improvement in the business performance.

In [16], the authors analyzed the impact of ERP system adoption on business performance and innovation using a survey based technique. They surveyed 200 small and medium enterprises in Saudi Arab and results were based on 120 valid responses. The results of study showed that ERP system helps increase an organization business performance and ERP adoption is also dependent on the individual training, user performance and support from the management.

\section{Research Objectives}

From literature review and discussion with experts, we find that ERP system implementation in an organization can impact business performance depending on how an individual organization approaches its adoption. Therefore, in this context we have conducted a study in Pakistan, with following main research objectives.

- Analyzing the impact of ERP system application and an organizations business process performance.

- Understanding the impact of organizational resistance to new system and business process performance

- Investigating the influence of individual training and its impact on the business process performance.

- Exploring the effect of the individual performance on business process performance improvement. 


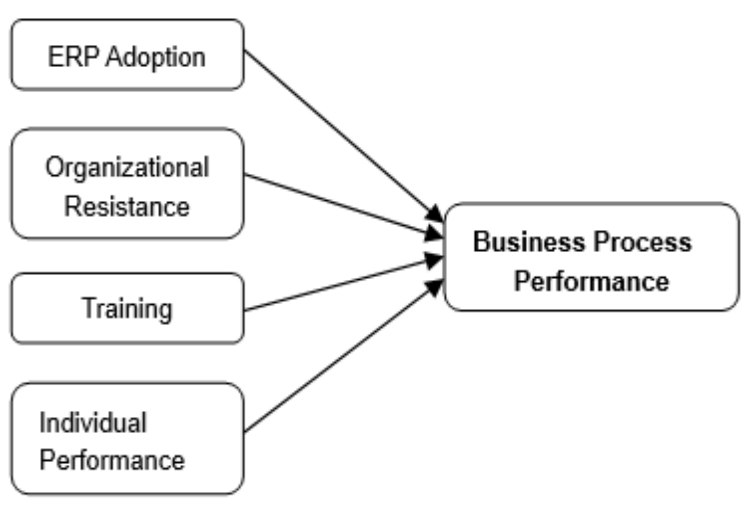

Fig. 1: Conceptual framework

Based on these research questions, following four hypotheses are developed and tested in a quantitative study.

- H1: There is a significant relationship between ERP Adoption and Business process performance.

- H2: Organizational resistance and business process performance have positive relationship using change management practices.

- H3: Training of employees plays a vital role for Business process performance.

- H4: An individual performance has positive relation-ship with Business process performance.

Figure 1 shows the conceptual framework based on the research objectives.

\section{Research Methodology}

The main objectives of this work was to find out the relationship between business process performance and ERP adoption by an organization. The organization selected were the firms from Karachi, Pakistan. A questionnaire based survey was conducted from 100 experts in these firms. The questionnaire was answered by the experts using a 5-point Likert Scale from 1 to 5 with options varying from 'strongly disagree' (1) to 'strongly agree' (5). The Ordinary Least-Squares (OLS) Regression Model [17] has been applied after the satisfaction of reliability of data using the basic regression model.

$$
Y=b_{0}+b_{1} x_{1}+b_{2} x_{2}+b_{3} x_{3}+\ldots \ldots \ldots \ldots+\mu
$$

In this study, we estimate the effect of ERP Adoption (AD), Organizational Resistance (OR), Training (TR) and Individual Performance (IP), also called predictors, on the Business process performance (BP), the

\begin{tabular}{|l|l|}
\hline Cronbach's Alpha & N of Items \\
\hline .864 & 24 \\
\hline
\end{tabular}

TABLE 1: Reliability Statistics

dependent variable. Therefore, our regression model in Equation 1 is modified accordingly as follows.

$B P=b_{0}+b_{1} A D+b_{2} O R+b_{3} T R+b_{4} I P+\ldots \ldots \ldots+\mu$

In the next section, we discuss the results obtained and their implication.

\section{Results \& Discussion}

The responses of the survey were analyzed with Ttest using SPSS. Table 1 shows the cost of Cronbach's Alpha (0.864) which is nearly equal to 0.9 , and shows a suitable justification for the reliability of data collection and the internal data consistency. Therefore, the data collection is reliable for an addition statistical evaluation. The goodness fit and reliability of Model is tested us-ing ANOVA [18] and the adjusted R square. Table 2 shows summary of the model. It provides a fairly cor-rect rationalization value of 0.771 (value of the adjusted $\mathrm{R}$ square), which is nearly 0.8 . TheThe table 3 shows the result of ANOVA. The significant value is nearly zero and is much less than 0.05 . Fcost is likewise enormous and it shows that ANOVA check is sizeable and consequently the null speculation of equality of all manner may be rejected. The ANOVA result signifies the model match for Regression. Table 4 provides the results of Regression model. The model for the Business process performance would now include values for the coeffecient as well, which are giv-en in the table 4 . The modified model is as follows:

$B P=.92+.73 A D+-.489 O R+.085 T R+.42 I P+\ldots+\mu$

The beta value for training is less insignificant due to the fact that its beta value is 0.258 which is more than the significant value (0.05). The rest of predictor beta values are all significant, i.e., their values are less than 0.05. It shows that there is a significant relationship between our three predictive variables ERP Adoption $(\mathrm{AD})$, Organizational resistance (OR) and Individual Performance (IP) and our dependent variable, the business process performance (BP). Considering our hypothesis H1, the results show that there is a direct relationship between ERP adoption and business process performance. It indicates that ERP can impact an organization business process performance. This result can help convince small to medium enter-prises in Pakistan to adopt ERP in their business process 


\begin{tabular}{|l|l|l|l|l|}
\hline Model & R & R Square & Adjusted R Square & Std. Error of Estimate \\
\hline 1 & $.883 \mathrm{a}$ & .780 & .771 & .329 \\
\hline
\end{tabular}

TABLE 2: Model Summary

\begin{tabular}{|l|l|l|l|l|l|}
\hline Model & Sum of Squares & Df & Mean Square & F & Sig \\
\hline Regression & 36.541 & 4 & 9.135 & 84.4 & $.0 \mathrm{a}$ \\
\hline Residual & 10.288 & 95 & .108 & & \\
\hline Total & 46.829 & 99 & & & \\
\hline
\end{tabular}

TABLE 3: ANOVA $^{\mathrm{b}}$

\begin{tabular}{|c|c|c|c|c|c|}
\hline \multirow[t]{2}{*}{ Model } & \multicolumn{2}{|c|}{$\begin{array}{l}\text { Unstandardized } \\
\text { Coefficients }\end{array}$} & \multirow{2}{*}{$\begin{array}{l}\text { Standardized } \\
\text { Coefficients } \\
\text { Beta }\end{array}$} & \multirow[t]{2}{*}{$\mathbf{t}$} & \multirow[t]{2}{*}{ Sig. } \\
\hline & $\mathrm{B}$ & Std. Error & & & \\
\hline (Constant) & .923 & 277 & & 3.328 & .001 \\
\hline ERP ADOPTION & .732 & .107 & .549 & 6.852 & .000 \\
\hline ORGNIZATIONAL RESISTANCE & -.489 & .096 & -.320 & -5.116 & .000 \\
\hline TRAINING & .085 & .074 & .079 & 1.138 & .258 \\
\hline INDIVIDUAL PERFORMANCE & .424 & .052 & .524 & 8.203 & .000 \\
\hline
\end{tabular}

TABLE 4: Coefficients

performance.

Our second hypothesis $\mathrm{H} 2$ is also supported by the results of the survey. It shows that the change management is important for creating positive impact on business process performance. As organizational resistance exists when a new system is adopted but change management initiative can channel it in the positive direction.

Though third hypothesis, i.e., 'individual training plays vital role for business process performance', is supported less by the results. It can be the result of individual unsatisfaction with the training provided by the top management. It can also be the result of our culture of forcing things upon employees instead of giving the training and development opportunities. The fourth hypothesis, i.e., 'individual performance impacts positively on the business process performance', is well supported by the results. It clearly shows how individual satisfaction leads to performance increase and consequently improving an organization's business process performance.

Overall, the outcome of the study clearly supports the three objectives of the research investigated through testing the three hypothesis and the fourth one is less supported and needs further exploration. The respondents agreed that the ERP adoption from ERP department greatly impacts an enterprise's performance. The respondents also accept that organizational resistance can be managed through management initiatives, as with all new technology there is a resistance to change and it should be tackled as early as possible. Further, it becomes clear that user satisfaction leads to improved individual performance and it boosts organizational performance as well.

The hypothesis less supported is related to the individual training's impact on the organizations business performance. Logically, an individual's training should enhance an organization business performance as training and development boosts individual potential and helps him/her to be more efficient and effective. It seems that the respondents could not signify its vital role, so there is a need to explore it further. The reason why an individual member has less value of staff training is either due to a cultural phenomenon or the organizations are not providing adequate training and development facilities at their part.

\section{Conclusion}

This work has shown that the implementation of ERP system has good impact on an organizations business performance. There are different factors that contribute to this anticipated improvement. One of the important factors is the early adoption of ERP system. The adoption of ERP system must be complimented by the support from the top management which includes management initiative to manage the change. As there is usually an organizational resistance to change, it should be managed quickly to make it a positive outcome for the organization. There should be an understanding that there will be a resistance and an organization that is able to implement a policy that caters to the resistance will be successful in improving its performance. Also, information systems like ERP 
help enhance individual performance and that should also help improve an organizations business process performance. Therefore, it can be concluded that business performance measurement of an organization implementing ERP system improves significantly. It is mainly the result of three different perspectives. The three perspectives out of four including ERP adoption, organizational resistance and individual performance perspective have a remarkable contribution in improving business process performance of the organization as well as its overall performance.

In future, we will investigate why individual training was less significant for the employee; whether it was due to cultural norms in the organizations in our country or it was due to some other factors. In general, an individuals training and development leads to the positive individual performance and consequently should help improve an organization's performance as well. The organizational culture and management support is vital for providing good working environment. Therefore, the aspect related to individual training requires further exploration and it needs to be analyzed in detail with respect to individual retention of an organization and should be analyzed further.

\section{References}

[1] Nawaz, Nishad \& Channakeshavalu. "The Impact of Enterprise Resource Planning (ERP) Systems Implementation on Business Performance", in SSRN Electronic Journal, 2013.

[2] Li, Y., "ERP adoption in Chinese small enterprise: an exploratory case study", Journal of Manufacturing Technology Management, Vol. 22, No. 4, pp. 489-505, 2011.

[3] Foster S., Hawking P., Zhu C., "The Human Side of ERP Implementations: Can Change Management Really Make a Difference?", in Research and Practical Issues of Enterprise Information Systems II. IFIP - The International Federation for Information Processing, vol. 254, Springer, Boston, MA, 2007.

[4] Muzammil H., Yasir S. K., Arshad Z., "Impact of Organizational Resistance to Change on BPR Implementation: A Case of State Bank of Pakistan", European Journal of Business and Management, Vol.6, No. 4, 2014.

[5] Ahmed, Zafar \& Zbib, Imad \& Sawaridass, Arokiasamy \& Ramayah, T. \& Lo, May chiun. "Resistance to change and ERP implementation success: The moderating role of change management initiatives." Asian Academy of Management Journal. Vol 11, 2006.

[6] Mahmud, I., Ramayah, T., \& Kurnia, S. "To use or not to use: Modelling end user grumbling as user resistance in pre-implementation stage of enterprise resource planning system", Information Systems, Vol. 69, pp. 164-179, 2017.

[7] Peter Trkman, "The critical success factors of business process management", in International Journal of Information Management, Vol. 30, No. 2, pp. 125-134, 2010.

[8] Van Looy, A., Shafagatova, A. Business process performance measurement: a structured literature review of indicators, measures and metrics. SpringerPlus, Vol. 5, 2016.
[9] Börner, R., Moormann,J., Wang M., "Staff training for business process improvement: The benefit of role-plays in the case of KreditSim", in Journal of Workplace Learning, Vol. 24, No. 3, 2012.

[10] Glykas M.M, "Effort Based Performance Measurement in Business Process Management", in Knowledge and Process Management, Vol. 18, No. 1, pp 10-33, 2011.

[11] González-Rojas, O., \& Lesmes, "Value at risk within business processes: An automated IT risk governance approach", in the International Conference on Business Process Management, pp. 365-380, 2016.

[12] Hasan, Najmul, Shah Jahan Miah, Yukun Bao, and Md Rakibul Hoque. "Factors affecting post-implementation success of enterprise resource planning systems: a perspective of business process performance." Enterprise Information Systems, Vol. 13, No. 9, pp. 1217-1244, 2019.

[13] Aremu, A. Y., Shahzad, A., \& Hassan, S., "The empirical evidence of enterprise resource planning system adoption and implementation on firm's performance among mediumsized enterprises." Global Business Review, 2019.

[14] Alomari, I. A., Amir, A. M., Aziz, K. A., \& Auzair, S. M., "Effect of enterprise resource planning systems and forms of management control on firm's competitive advantage." Asian Journal of Accounting and Governance, Vol. 9, pp. 87-98, 2018.

[15] Sutduean, J., Singsa, A., Sriyakul, T., \& Jermsittiparsert, K., "Supply Chain Integration, Enterprise Resource Planning, and Organizational Performance: The Enterprise Resource Planning Implementation Approach." Journal of Computational and Theoretical Nanoscience, Vol. 16, No. 7, pp. 2975-2981, 2019.

[16] AlMuhayfith S, Shaiti H. "The Impact of Enterprise Resource Planning on Business Performance: With the Discussion on Its Relationship with Open Innovation." Journal of Open Innovation: Technology, Market, and Complexity, Vol.6. No. 3, pp. 87, 2020.

[17] Zdaniuk B., "Ordinary Least-Squares (OLS) Model." In: Michalos A.C. (eds) Encyclopedia of Quality of Life and Well-Being Research, Springer, 2014.

[18] Michael H. HerzogGregory FrancisAaron Clark, "ANOVA," in book Understanding Statistics and Experimental Design, Learning Materials in Biosciences. Springer, pp 67-82, 2019. 